\title{
The Spatial Impacts of Covid-19 and Households Behavioural Changes in Akure, Nigeria
}

\author{
A. R. Olubi and H. A. Ayoola
}

\section{ABSTRACT}

Individuals' spatial experiences differ but, in many cases, the local environment and the society at large constitute huge influences on life experiences. COVID-19 is the current life experience that affects physical, societal, as well as residential wellbeing globally. It causes radical changes in the meaning, perception, and individual behaviours in and around residential housing spaces with lots of implications worth researching. This paper through survey examined the spatial experiences presented by the pandemic; its impacts on the spaces and other factors that constitute huge changes in human household behaviours within the low-income neighbourhoods in Akure, Nigeria. It was discovered that individual houses serve as the first line of defence against COVID-19; the lockdown imposed on cities and other precautionary measures also necessitated voluntary and involuntary behavioural changes which become visible in many households, these changes may likely be sustained after the pandemic. The paper emphasizes the need to reinforce the built environment against pandemics and also to ensure that post-pandemic residential housing designs are flexible, easily adaptable, upgradeable, and sustainable.

Keywords: Behavioural Changes, COVID-19, Households, Spatial Effects

Published Online: December 30,2021

ISSN: 2736-5522

DOI: $10.24018 /$ ejsocial.2021. 1.6.58

\section{A. R. Olubi*}

Department of Architecture, Ajayi Crowther University, Oyo, Nigeria. (e-mail: ar.olubi@ acu.edu.ng) H. A. Ayoola Department of Architecture, Federal University of Technology Akure, Nigeria (e-mail: ha.ayoola ${ }^{@}$ futa.edu.ng)

*Corresponding Author

\section{INTRODUCTION}

COVID-19 pandemic with its numerous consequences induces so many effects on societal and residential lifestyles. Social life and interactions are reduced tremendously, while many households experienced a series of drastic shifts or complete changes in their usage of spaces. The pandemic necessitates an enormous reduction in the efficiency and management of household spaces thus leading to an increase in daily worries (Altena et al., 2020). Narayanan et al. (2020) posit that the pandemic affects physical health with lots of implications on emotional and social functioning; such that behavioural changes and a high-level spatial reliance become necessary in containing the spread of the virus. This further buttresses the efficacy of the urban built environment (homes inclusive) in lessening the impacts and combating the spread of the pandemic (Megahed \& Ghoneim, 2020).

Cities lockdowns, stay-at-home, work-from-home, and social/physical distancing were some of the non-pharmaceutical measures (Narayanan et al., 2020) imposed to combat the spread of the pandemic; these brought varying degrees of changes in human behaviours within social and households' spaces. They were as well responsible for different challenges in lifestyles and human activities (Cho, 2020) with residents of large and crowded households mostly affected (Saadat et al., 2020; Megahed \& Ghoneim, 2020). However, Ainsworth et al. (2020) argued that the stay-at-home concept only increased the risk of spread of the virus within households, but the position failed to ascertain the comparative level of "transmissibility" within and in-between households (Jing et al., 2020). Arguably, COVID-19 restrictions put a complete stop to the usual, vibrant, and lively social interactions, and if truly these restrictions exposed households' members to the risk of contracting the virus, then major behavioural changes within households cannot be overemphasized.

The diverse behaviours of individuals in spaces can be ascribed to their choices which are enshrined in the "concepts of perception and cognition" (Golledge \& Stimson, 1997; James, 2020). The concept explains the individuals' usage of spaces and the meaning assigned, which are oftentimes isolated from the attachment, life experiences, and memories of the spaces (Montello, 2013; James, 2020). Fadamiro (2015) argued that human behavioural changes can either be "free-will, deterministic, probabilistic or possibilistic". The deterministic approach posits that the human immediate environment poses a great effect on human behaviour such that any change(s) in the design or arrangement of human spaces causes a similar effect on human behaviour. Bringing this discussion close to the individual households could mean that the spatial effects of COVID- 19 tend to cause behavioural changes in the residents at the 
geographical and individual spatial levels (James, 2020).

The current health crisis requires a rethink in the design and development of household spaces and the entire built environment (Chang, 2020). Curtailing the spatial impacts of COVID-19 and "preventing households' spreads" requires not only the design of isolation centres but also the development of allencompassing design solutions for different building types and the entire urban environments (Saadat $e t$ al., 2020) that accommodates different behavioural changes, and enhances human, social as well as environmental health. This can be achieved through the design, redesign, and reconfiguration of households and environmental spaces towards lessening and combating the pandemic. This article is therefore put forward to know the possible extent of such changes, the effects, likely survival strategies as well as to provide logical predictions for a possible post-COVID-19 lifestyle in the low-income neighbourhoods in Akure Nigeria.

\section{Spatial Impacts of COVID-19 ON Household Spaces}

The human society at large consists of several important structures; one of such is the residential households with a varying hierarchy of human interactions (Watts et al., 2005; Ball et al., 2015). According to Jasiński (2020), households' spaces are highly rated and "highly valued" during the COVID-19 pandemic because of the "invaluable safety and the mental comfort" they provided. The "work-from-home" or "business-from-home" restriction of COVID-19 justifies the capacity of household spaces to accommodate diverse uses on one hand and to advance residents' safety and wellbeing on the other hand. Many discoveries of household spatial potentials were made such as "additional functions for established spaces, corners, small spaces, and balconies" among others (Adediran et al., 2020). Households' spaces are generated following regulated and appropriate codes, laws, and standards that are "contextual and value-laden" to design principles and spaces ergonomics. Common minimum household spaces are based on human-space ratio, anthropometrics, and spatial analysis (Honey-Roses et al., 2020). However, COVID-19 experience and safety precautionary measures made the already established spatial dimensions inadequate to accommodate functions with impending radical changes (Honey-Roses et al., 2020).

The need therefore to advance residents' wellbeing and safety against possible infection of current COVID-19 and future pandemics within household spaces become an utmost necessity (Adediran et al., 2020). It is expected of future households' spaces to defile regulatory minimum standards and as such, new interior space metrics to emerge. Meanwhile, such envisioning households' spaces must ultimately be designed to consider any other likely impacts on the city-building and design process (Van der Berg, 2020). This advances the call for changes in the regulations and planning of the residential interior spaces to align with the COVID-19 specifications, which would have long-term consequences on household spaces. The internal spatial dimensions, their arrangements together with the "associated footprints" would grow considerably and cause huge positive effects on the spatial needs, available household spaces, and characteristics that will transverse the entire urban spaces (Van den Berg, 2020; Honey-Roses et al., 2020).

\section{Household’s Behavioural Changes AND the NEED FOR IMPROVED BuILDing DESIGNS}

Spatial satisfaction is derived when individuals' "life experience and memories are connected with their spaces (Montello, 2013; James, 2020). Currently, COVID-19 is the life experiences that define human spaces, uses, meanings, satisfactions, and behaviours. Cho, (2020) argued that COVID-19 affects "boundaries and challenge the usual household behaviours". The different restrictions imposed altered the usual practices in many homes in an attempt to balance work with other non-work-related activities; and also to prevent households' members from contracting the virus. People with a high inclination for workfamily separations are highly affected; also those with high family demands were distracted, had their boundaries interrupted and behaviours changed.

In reality, preventing the spread of COVID-19 within households requires behavioural changes slightly, frequently, or regularly depending on the circumstances. For instance, the need to shield highrisk household members such as the elderly and the children within households and (or) to be protected from a household member with symptoms requires firm behaviours measures. This has been ascertained potent in limiting the occurrences, impacts, and ruthlessness of the diseases (Ainsworth et al., 2020). However, the potency of household behavioural changes is limited by different factors particularly the conventional spatial configurations of residential households which in many circumstances seem so rigid and do not permit social distancing and self-isolation (Atchison et al., 2020; Ainsworth et al., 2020).

The global pandemic has revealed that architecture and urbanism need re-examinations of design approaches and planning assumptions towards creating healthy housing designs, less polluted housing 
environments, and more sustainable architecture. Further improvements are needed to make residential housing designs effectively align with social isolation and offer protection against future viruses and infections; they are expected to explore all transformational options of functionality, creativity, flexibility, and adaptability where necessary. The magical healing effects of light, air, and nature on human health should be maximized through flexible and adaptable design options (Chang, 2020) through which housing spaces and environments are made sustainable, easily adjustable to different needs, circumstances, and lifestyles (Capolongo et al., 2020; Wainwright, 2020; Megahed \& Ghoneim, 2020). Extremely high densities and overcrowding neighbourhoods must be discouraged, slums must be cleared and the human environment is redefined. It is therefore important that post-COVID-19 housing designs must meet the safety needs of the users through the use of adequate safety design considerations, spatial configurations, and the use of infill materials that are flexible enough to ensure that spaces are adaptable and meet various future needs without jeopardizing the privacy of the occupants; such spaces must be easy to redesign and reconstruct at any time depending on needs, safety and lived experience (Aryan \& Jen-Tu, 2020).

\section{Methodology}

Akure, a medium-sized city in Southwest Nigeria is the capital of Ondo State, Nigeria as well as the administrative headquarters of Akure South Local Government Area. It is one of the renowned towns in the old Western region of Nigeria and it has been in existence ever before the advent of British colonial rule in Nigeria (Olajuyigbe et al., 2016). Akure lies between latitude $7^{0} 21^{\prime} \mathrm{N}$ and $7^{\circ} 50^{\prime} \mathrm{N}$ and Longitude $5^{0} 50^{\prime} \mathrm{E}$ and $7^{0} 25^{\prime} \mathrm{E}$. It is located about 370 meters above sea level with a total land area of 331 square kilometers (Olugbamila, 2018). The population of the city was estimated as 360,268 during the 2006 population census (NBS, 2011) and with the projected annual growth rate of $3.03 \%$, the population of Akure is currently estimated as 524, 010. The city enjoys a continuous urban population growth because of its administrative and economic capacities as well as its classification as a Millennium Development City (Olugbamila, 2018; Fakere et al., 2017). Akure has witnessed continuous population and urban growth without commensurate planning. This phenomenon is responsible for the increase in urban challenges as well as the development of slums in the ever concentrated low-income neighborhoods at the urban core (Olamiju \& Oyinloye, 2015). Ayoola et al. (2019) identified twelve residential zones in Akure among which four zones namely Erekesan/Erekefa, Idiagba/Ijemikin, Obanla/Ijomu, and Araromi/OdoIjoka/Old stadium are at the core of the city as shown in figure 1. These residential zones are classified as the poverty-dominated areas within the city and they are equally referred to as the low-income residential neighborhoods in this study.

The study is designed to quantitatively answer several research questions bothering on the COVID-19 pandemic and the household spaces in a low-income neighbourhood in Akure Nigeria. It sets out to probe how the pandemic affects the uses of residential spaces, how the relationship with individuals' spaces was affected, the behavioural changes experienced, and the lessons for the future design of residential houses. Primary data were collected using a structured online questionnaire administered to randomly selected household members of eighteen years and above within the study area. It is believed that people of these age groups have a good understanding of the subject and should be willing to share their experiences during COVID-19 lockdowns regarding the spatial impacts and behavioural changes. A total of 300 questionnaires were administered from which 250 were retrieved, data gathered were analyzed, and conclusions deduced. This survey is targeted at the residents of low-income residential neighbourhoods in Akure, Nigeria because of the difficulties in observing "self-isolation" and other safety precautions in such neighbourhoods. Many households in the neighbourhoods share housing facilities and experience greater spatial impacts that would require behavioural changes to face the reality of the pandemic. Although COVID-19 is not environmental specific, its spread covers diverse neighbourhoods irrespective of the classes in the society, the result of the study is therefore applicable to low-income neighbourhoods only while further study into the spatial impacts on the high-income neighbourhoods is encouraged. 


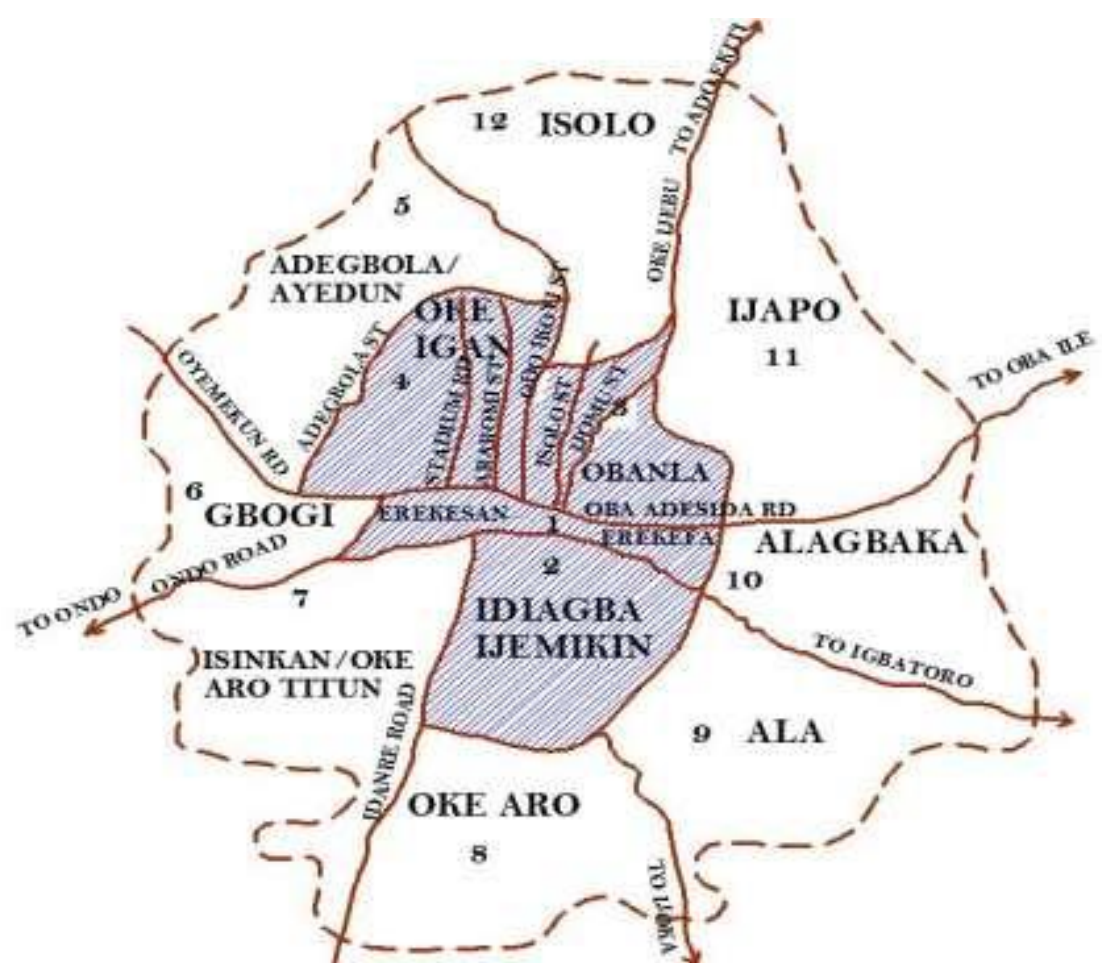

Fig. 1: The residential zones in Akure, Nigeria (Ayoola et al., 2019)

\section{RESULTS AND DISCUSSIONS}

Issues bothering on COVID-19 pandemic, its impact on household spaces, and the behavioural changes require an in-depth understanding of the configuration, characteristics, and uses of residential household spaces. In other to arrive at a transparent survey, Table I reports the socio-demographic of the respondents and reveals their gender distributions as 58\% males to $42 \%$ females. COVID-19 affects both genders alike which is responsible for almost a balance in the respondents' gender. Probing the different ages of the respondents' reveals that $31 \%$ are within the ages of $18-30$ years, $58 \%$ are within the ages of 31- 45 years, $5 \%$ are within the ages of $46-55$ years, $4 \%$ are within the ages of $56-65$ years of age while about $2 \%$ are above the ages of 65years. This indicates that the study covers a larger population of the respondents that are in their active working years (18 - 65 years). They are mostly affected by COVID-19 restrictions such as stay-at-homes and work-from-home; they are actively and daily engaged in spaces for formal and informal activities within their homes hence more exposed to the spatial imbalance created by the pandemic. Fewer percentages of the respondents are above 65years; these respondents are important as well and must be protected from contracting the virus.

The highest educational level of the respondents indicates that about $4 \%$ have Ph.D. degrees, $38 \%$ have Master's degrees, 23\% have B.Sc/B.Tech/B.Ed degrees, and 23\% have Diploma while about $12 \%$ have Senior School Certificates. This result indicates that the respondents are literate with different levels of formal education and certifications; it is thus expected that the respondents should have a good understanding of the subject under investigation.

The tenure system investigated reveals that $77 \%$ of the respondents are tenants while $23 \%$ are owners of varying degrees. The family sizes of the respondents were probed into and revealed that $23 \%$ of respondents have less than 3 family members living together, 69\% have between 4 and 6 family members, $8 \%$ have between 7 and 10 members while none of the respondents have household size above 10 members. This indicates that the highest proportion of the respondents has family sizes between 4 to 6 which is significant to the subject matter. 
TABLE I: SOCIO-DEMOGRAPHIC DISTRIBUTIONS OF THE RESPONDENTS

\begin{tabular}{ccc}
\hline \hline Distributions & Frequency & $(\%)$ \\
Gender & & \\
Male & 144 & 57.6 \\
Female & 106 & 42.4 \\
Age & & \\
$18-$-30years & 77 & 30.8 \\
$31-$-45years & 146 & 58.4 \\
$46-$ 55years & 13 & 5.5 \\
$56-65$ years & 9 & 3.6 \\
Above 65years & 5 & 2.0 \\
SSCE & & \\
Highest Educational Qualification & 29 & 11.6 \\
NCE/OND/HND & 58 & 23.2 \\
B.Sc./ B.Tech./ B.Ed. & 58 & 23.2 \\
Masters Degree & 96 & 38.4 \\
Ph.D. & 9 & 3.6 \\
Type of Occupancy & & \\
Rented Apartment & 192 & 76.8 \\
Owner-Occupied & 58 & 23.3 \\
Household sizes & & \\
Below 3 & 58 & 23.3 \\
4-6 & 173 & 69.2 \\
$7-10$ & 19 & 7.6 \\
Above 10 & 0 & 0 \\
\hline
\end{tabular}

Source: Author's field survey (2020)

Table II probes the different households' spatial re-arrangements occasioned by the pandemic. It was revealed that much pressure was on the living rooms being the only public space in many homes as $92 \%$ of the respondents affirmed that their living rooms spaces were rearranged/altered or reconfigured during the restriction period to accommodate other activities. The remote working model adopted by many organizations during the period made many to carve out working spaces from the living room; learning and playing took place in many living spaces since interactions within the neighbourhood were completely discouraged due to the fear of contracting the disease, and many people also added sleeping to the functions of their living spaces during the period to discourage overcrowding and possible infection within the households. These created much impact on the existing living spaces whereas; only $8 \%$ of the respondents did not alter the arrangement and function of their living spaces and thus no spatial impact of the pandemic on their living areas. This study corroborates Megahed and Ghoneim (2020); Rosel, (2020); Honey-Roses et al., (2020) that COVID-19 restrictions significantly distort residential life and also create spatial effects on the already shattered conventional uses of residential spaces which necessitates a different form of rearrangements to accommodate other uses and functions.

Other likely functions carried out in the bedrooms by the respondents other than sleeping during the COVID-19 period was probed into and it was discovered that $88 \%$ of the respondents created spaces in their bedrooms to carry out other related and unrelated activities such as official assignments, informal businesses, studying, reading among others. It was also noted that $12 \%$ of the respondents did not alter the function and arrangements of their bedrooms during the period. $85 \%$ of the respondents affirmed rearranging their dining spaces to accommodate other functions during the COVID-19 lockdown period, while $15 \%$ of the respondent did not alter the arrangements nor reconfigure their dining spaces. Only $12 \%$ of the respondents used their kitchens for business activities during the restriction period while $88 \%$ of the respondents did not re-arrange or alter the function of their kitchens.

It can be argued that COVID-19 necessitates a different kind of spatial re-arrangements and adjustments within residential households which negatively affect the nature, function, and uses of the household spaces and thus create a spatial imbalance. This position corroborates Honey-Roses, (2020) that COVID-19 brought about alterations of the conventional interior spaces within residential homes such that significant transformations in uses took place during the lockdowns period.The period justifies the capacity of household spaces to accommodate diverse uses on one hand and to advance residents' safety and wellbeing on the other hand (Adediran et al., 2020) but not without negative impacts on the already exhausted and problematic conventional residential spaces. 
TABLE II: HOUSEHOLDS’ SPATIAL ADJUSTMENTS AND RE-ADJUSTMENTS EXPERIENCED DURING COVID-19

\begin{tabular}{ccc}
\hline Distributions & Frequency & $(\%)$ \\
\hline \hline Living rooms were re-arranged to accommodate other functions & 231 & 92.4 \\
No re-arrangements or alteration of living spaces & 19 & 7.6 \\
Bedroom spaces were re-arranged to accommodateother functions & 220 & 88.0 \\
No re-arrangements of bedroom spaces & 30 & 12.0 \\
Dining spaces were re-arranged & 212 & 84.8 \\
No re-arrangements of dining spaces & 38 & 15.2 \\
The kitchen was used for informal businesses & 28 & 11.2 \\
No alteration in the use of kitchen & 222 & 88.8 \\
\hline \hline
\end{tabular}

Source: Author's field survey (2020)

Investigating the impacts of COVID-19 on the individual's relationship with household spaces as shown in Table III reveals that $69 \%$ of the respondents had their relationships with their personal spaces within their homes intact despite different spatial changes, arrangements, and alterations faced during the lockdown period. Whereas $31 \%$ of the respondents were affected by the different spatial adjustments such that their interactions and relationships with their personal spaces were altered, inadvertently hindered, and adversely affected. During COVID-19 restrictions, 54\% of the respondents had their relationships with personal spaces negatively affected because more people were at home to share the available spaces which affected individuals' relationships with personal spaces; while $46 \%$ of the respondents were not affected in any way. For the fear of contracting COVID-19 at home, only $23 \%$ of the respondents limited their relationships and interactions while $77 \%$ of the respondents did not limit their relationships within their household spaces. This result supports Jasiński (2020) that the value of personal spaces increased significantly during the pandemic period through which important safety and undeniable mental comforts were provided. It can therefore be affirmed that individuals' relationships with household spaces were not affected by COVID-19; instead, homes spaces supported different human activities. The significance of individual homes in curtailing the spread of the virus cannot be overemphasized as $70 \%$ of the respondents agreed that individual homes were the first and major place of defence against the pandemic; whereas, $30 \%$ of the respondents believed that the rate of spread of the virus increases within households. The extent of reduction of the spread of the virus within homes is said to be highly significant as shown by 53\% of the respondents. This result contradicts Ainsworth et al. (2020) that stay-at-home restriction increases the risk of the spread of the virus within households.

TABLE III: THE IMPACTS OF COVID-19 ON INTERACTIONS AND RELATIONSHIPS WITH INTERIOR SPACES

\begin{tabular}{ccc} 
TABLE III: THE IMPACTS OF COVID-19 ON INTERACTIONS AND RELATIONSHIPS WITH INTERIOR SPACES & Frequency & $(\%)$ \\
\hline \hline Distributions & 173 & 69.2 \\
The relationship with personal spaces was affected by spatial re-arrangements & 77 & 30.8 \\
Spatial re-arrangements did not affect relationships & 135 & 54.0 \\
The relationship was intact despite more people sharing the spaces & 115 & 46.0 \\
The relationship with personal spaces was affected because more people at home to share the spaces & 58 & 23.2 \\
The relationship was affected because of the fear of being infected with the virus & 192 & 76.8 \\
The relationship was not affected despite the fear of being infected with the virus & 175 & 70.0 \\
Did staying at home or working from home reduce COVID-19 transmission within households? & 75 & 30.0 \\
Yes & 135 & 54.0 \\
No & 28 & 23.2 \\
To what extent did spatial changes reduce the spread of COVID-19? & 57 & 22.8 \\
Significantly Reduced & Fairly Reduced \\
No Reduction &
\end{tabular}

Source: Author's field survey (2020)

Investigating the possible behavioural changes within homes reveals that a total of $66 \%$ of the respondents took various behavioural precautions ranging from self isolations, restriction of movements and interactions within neighbourhoods, and wearing of face mask/shield at home to protect themselves and others within the same households from contacting the virus; whereas $34 \%$ of the respondents did not practice any of the afore-mentioned behavioural measures. It was discovered that before the COVID-19 pandemic, households enjoyed interactions without the fear of infections neither did they have any need for behavioural changes except for the practice of good hygiene as indicated by 55\% of the respondents.

Projecting post-COVID-19 lifestyle, this study reveals that maintaining personal hygiene remains paramount as indicated by $56 \%$ of the respondents, $12 \%$ of the respondents indicated limiting the number of visitors and movement of neighbours in and around their houses, $11 \%$ submitted to maintaining social distances from their family members; $12 \%$ shall constantly decontaminate surfaces within their homes; $5 \%$ shall restrict social interaction with neighbours while $4 \%$ indicated wearing of face mask within their homes. This result as reported in table IV confirmed the extent to which COVID-19 affects human behaviours within households. Worthy of note is the fact that people are getting accustomed to the different behavioural changes caused by the pandemic as this might define life henceforth; when 
households lifestyle shall embrace and improve on the safety protocols, knowledge, and behavioural changes developed during the pandemic (Cho, 2020). This result provides an update on James (2020) which noted the changes in human behaviour during COVID-19 within public spaces but could not ascertain the duration of such changes considering the factors of time, politics, and other essential needs.

TABLE IV: HOUSEHOLDS’ BEHAVIOURAL CHANGES DURING COVID-19

\begin{tabular}{|c|c|c|}
\hline Distributions & Frequency & $(\%)$ \\
\hline \multicolumn{3}{|l|}{ Were You Afraid of Contracting COVID-19 through Households Members? } \\
\hline Yes & 86 & 34.4 \\
\hline No & 164 & 65.6 \\
\hline \multicolumn{3}{|l|}{ Behavioural Responses adopted During COVID-19 } \\
\hline Self Isolation & 0 & 0.0 \\
\hline Restriction of movements within neighbourhoods & 79 & 31.6 \\
\hline Restriction of social interactions within the neighbourhoods & 67 & 26.8 \\
\hline Wearing of face mask & 19 & 7.6 \\
\hline None & 85 & 34.0 \\
\hline \multicolumn{3}{|l|}{ Before COVID-19 Pandemic, Safety Measures Practiced within Homes } \\
\hline Self-isolation and separation from other members of your households & 0 & 0.0 \\
\hline Restriction of neighbours movement in and around your apartment & 72 & 28.8 \\
\hline Restriction of social interactions with the neighbours & 20 & 8.0 \\
\hline Constant decontamination of surfaces & 12 & 4.8 \\
\hline Personal hygiene & 138 & 55.2 \\
\hline None & 8 & 3.2 \\
\hline \multicolumn{3}{|l|}{ Possible Post COVID-19 Behavioural Changes } \\
\hline Restriction of neighbours movement in and around your house/apartment & 31 & 12.4 \\
\hline Restriction of social interaction with neighbours & 12 & 4.8 \\
\hline Continuous social distancing & 28 & 11.2 \\
\hline Continuous wearing of face mask/shield & 10 & 4.0 \\
\hline Constant decontamination of surfaces & 29 & 11.6 \\
\hline Personal hygiene & 140 & 56.0 \\
\hline
\end{tabular}

Source: Author's field survey (2020)

The need to improve residential spaces for household satisfaction and also to limit the spatial impacts of the pandemics on household spaces was investigated and reported in Table V. 19\% and $73 \%$ of the respondents strongly agreed and agreed respectively that residential spaces need to be made more flexible to allow easy re-arrangement/adjustments/alteration in case of the future pandemic; whereas $4 \%$ of the respondents each were undecided and strongly disagreed respectively. A total of $92 \%$ of the respondents want other functioning spaces such as offices, study, children's play areas added to all future residential designs to prevent unnecessary re-arrangements of spaces during emergencies; while $8 \%$ of the respondents completely disagreed. On the concern for post-pandemic lifestyle, $27 \%$ and $35 \%$ of the respondents strongly agreed and agreed respectively that residential spaces need to be made adaptive to various functions; while $31 \%$ of the respondents were undecided possibly because of a lack of understanding of the question, a total of $8 \%$ of the respondents disagreed. Considering the human environments, all respondents agreed to regular and continuous maintenance of environmental health and hygiene as one of the potent ways of combating pandemics. This study, therefore, affirms the results of Megahed and Ghoneim (2020): Chang (2020) that COVID-19 exposes the importance and value of individual homes and the need for improvements in design and planning to explore all transformational options such as flexibility, adaptability, and sustainability among others. The supernatural healing effects of natural ventilation and sunlight must be utilized and incorporated into building designs through flexible and adaptable design options. 
TABLE V: THE NEED FOR IMPROVED RESIDENTIAL SPACES

\begin{tabular}{cccccc}
\multicolumn{6}{c}{ TABLE V: THE NEED FOR IMPROVED RESIDENTIAL SPACES } \\
\hline Distributions & $\begin{array}{c}\text { Strongly } \\
\text { Agreed } \\
(\%)\end{array}$ & $\begin{array}{c}\text { Agree } \\
\mathrm{d}(\%)\end{array}$ & $\begin{array}{c}\text { Undecided } \\
(\%)\end{array}$ & $\begin{array}{c}\text { Strongly } \\
\text { Disagreed } \\
(\%)\end{array}$ & $\begin{array}{c}\text { Disagree } \\
\mathrm{d}(\%)\end{array}$ \\
\hline $\begin{array}{c}\text { The Need for Improved Residential Spaces for Spatial Satisfactions } \\
\text { and Reduce the Impact of Future Pandemics }\end{array}$ & & & & & \\
\hline $\begin{array}{c}\text { Use of flexible construction materials for easy reconfigurations } \\
\text { Compulsory inclusion of other important spaces to residential } \\
\text { buildings }\end{array}$ & 19.2 & 73.2 & 3.8 & 3.8 & 0.0 \\
$\begin{array}{c}\text { All residential spaces must be adaptive to different functions } \\
\text { pandemic }\end{array}$ & 26.9 & 34.6 & 30.9 & 3.8 & 3.8 \\
$\begin{array}{c}\text { Environmental hygiene must be sustained after the COVID-19 } \\
\text { Natural Ventilations and lighting must be incorporated into } \\
\text { residential spaces }\end{array}$ & 88.5 & 11.5 & 0.0 & 0.0 & 0.0 \\
\hline \hline
\end{tabular}

\section{CONCLUSION AND ReCOMmENDATIONS}

COVID-19 pandemic causes drastic shifts or complete changes in the usage of residential spaces. Households' spaces offer safety and undeniable mental comforts during the lockdown period. However, the pandemic also causes an enormous reduction in the efficiency, requirements, and management of household spaces thus necessitates spatial rearrangements, adjustment, or alteration within households which negatively affect the nature, functions, and uses of the spaces and as well creates an imbalance. Many of the precautionary measures needed to fight the pandemic demand serious changes in human behaviours within social and household spaces; this creates various challenges to lifestyles and activities as well as a high level of spatial reliance. This study, therefore, posits that COVID-19 hurts human behaviours within households' spaces of low-income residential neighbourhoods in Akure, Nigeria. These behavioural changes tend to define ways of life such that households' lifestyles may continually embrace and improve on the safety protocols, knowledge, and other changes developed during the pandemic.

Going forward, post COVID-19 housing design must ensure that spaces are safe without any negative impacts on the configurations, arrangements, and uses; adequate design considerations, spatial configurations, and the use of flexible design and materials that are adaptive to various future needs or pandemic must be embraced. More so, the need for improvement in the design and planning of residential housing and the entire human environment of the low-income residential neighbourhoods cannot be overemphasized. Now is the time to explore all transformational options, more importantly, the need for adaptable and sustainable residential housing design options for the poor, adequate considerations must be given to natural lighting, ventilation, social isolation, and protection against viruses and infections; high density and crowded neighbourhoods must be discouraged, slums cleared and human environments redefined.

\section{REFERENCES}

Altena, E., Baglioni, C., Espie, C.A., Ellis, J., Riemann, D., et al. (2020). Dealing with sleep problems during home confinement due to the COVID-19 outbreak: Practical recommendations from a task force of the European CBT-I Academy. Journal of Sleep Research. DOI: 10.1111/jsr.13052.

Adediran, A.O., Oladejo, S.O., Akinwande T.O., Ajibade S.M, Moveh, S. (2020). Housing Quality Standard and Covid-19 Pandemic: A Call for Attention in Nigeria. Journal of Science, Engineering, Technology and management.2(2). https://doi.org/10.46820/JSETM.2020.1105, 1-10.

Ainsworth, B., Miller, S., Denison-Day, J., Stuart, B., Groot, J., Rice, C., et al (2020). Current infection control behaviour patterns in the UK, and how they can be improved by 'Germ Defence', an online behavioural intervention to reduce the spread of COVID19 in the home. https://doi.org/10.1101/2020.06.22.20137406.

Aryan, N.P\&Jen-Tu,K. (2020). Environmental Behavior Analy sis of Social Housing Units in Surabaya, Indonesia. Journal of Asian Architecture and Building Engineering, DOI: 10.1080/13467581.2020.1799796, 1-31.

Atchison, C.J., Bowman, L., Vrinten, C., Redd, R., Pristera, P., Eaton, J.W., et al. (2020). Perceptions and behavioural responses of the general public during the COVID-19 pandemic: A cross-sectional survey of UK Adults; 1-21; medRxiv preprint DOI: https://doi.org/10.1101/2020.04.01.20050039.

Ayoola, H.A., Fakere, A.A., Olusoga, O (2019). Place Attachment in Poor Residential Neighborhoods of Akure Nigeria. Covenant Journal in the Research Built Environment (CJRBE), 7(2), 20-36

Ball, F., Britton, T., House, T., Isham, V., Mollison, D., Pellis, L., Tomba G, S. (2015). Seven challenges for the metapopulation model of epidemics, including household models. Epidemics $1 ; 63-67$; http://dx.doi.org/10.1016/j.epidem.2014.08.001

Budds, D. (2020). Design in the age of pandemics. available at: https://www.curbed.com/2020/3/17/21178962/design-pandemicscoronavirus-quarantine (Accessed 13 December 2020).

Capolongo, S., Rebecca, I A., Buffoli, M., Letizia, A., Carlo, S. (2020). COVID-19 and cities: From urban health strategies to the pandemic challenges. A decalogue of public health opportunities. Acta Biomedica. 91(2); 3-22; DOI: 10.23750/abm.v91i2.9515.

Centre for Disease Control CDC. (2020). COVID-19 guidance for shared or congregate housing. . available at https://www.cdc.gov/coronavirus/2019-ncov/community/shared-congregate-house/guidance-shared-congregate-housing.html (Accessed 13 December 2020). 
Chang, V. (2020). The post-pandemic style. https://slate.com/business/2020/04/coronavirus-architecture-1918-flu-choleramodernism.html(Assessed 13 December 2020).

Cho, E. (2020). Examining boundaries to understand the impact of COVID-19 on vocational behaviors. Journal of Vocational Behavior.https://doi.org/10.1016/j.jvb.2020.103437

Ellin, N. (1999). Postmodern urbanism. New York: Princeton Architectural Press.

Fadamiro J.A (2015). Behavioural Architetcture. Lagos: Graams print Lagos Nigeria.

Fakere, A.A., Arayela, O., Folorunso, C.O (2017). Nexus between the Participation of Residents in House Design and Residential Satisfaction in Akure, Nigeria. Frontiers of Architectural Research 6, 137-148;http://dx.doi.org/10.1016/j.foar.2017.02.003

Golledge, R.G, \& Stimson, R.J. (1997). Spatial Behavior: A Geographic Perspective. New York: The Guilford.

Honey-Roses, J., Anguelovski, I., Bohigas, J., Chireh, V., Daher, C., Konijnendijk, C., ... Nieuwenhuijsen, M. (2020). The Impact of COVID-19 on Public Space: A Review of the Emerging Questions; 1-20; https://doi.org/10.31219/osf.io/rf7xa.

James, A. (2020). Don't stand so close to me: Public spaces, behavioral geography, and COVID-19. Dialogues in Human Geography; XX(X); 1-4; DOI: 10.1177/2043820620935672.

Jasiński, A. (2020). Public space or safe space - remarks during the COVID-19 pandemic. Technical Transactions.https://doi.org/10.37705/TechTrans/e2020020.

Jing, Q., Liu, M., Zhang, Z., Fang, L, Yuan, J., Zhang, A., et al (2020). Household secondary attack rate of COVID-19 and associated determinants in Guangzhou, China: a retrospective cohort study; 1-10; Articles,https://doi.org/10.1016/S1473$3099(20) 30471-0$

Lubell, S. (2020). Commentary: Past pandemics changed the design of cities. Six ways covid-19 could do the same. available at: https://www.latimes.com/entertainment-arts/story/2020-12-13/coronavirus-pandemics-architecture-urban-design (Accessed 13 December,1 2020).

Megahed, N.A., Ghoneim, E.M. (2020). Antivirus-built environment:LessonslearnedfromCovid-19pandemic. Sustainable Cities and Society 61;1-9; DOI: 10.1016/j.scs.2020.102350.

Montello, D. (2013). Behavioral geography. In: Warf B (ed.) Oxford bibliographies in geography.New York: Oxford University Press.

Narayanan, R.P., Nordlund, J., Peace R.K., Ratnadiwakara. (2020). Demographic, jurisdictional, and spatial effects on social distancing in the United States during COVID-19 pandemic. PLoS ONE 15(9): e0239572. https://doi.org/10.1371/joutnal.pone.0239572, 1-27.

Olajuyigbe, A.E., Olamiju, I.O., Ola-Omole , C.M. (2016). Vulnerability of hand-dug wells in the core area of Akure, Nigeria.Urban Water Journal, 1-7; .http://dx.doi.org/10.1080/1573062X.2016.1254257

Olamiju, I.S., Oyinloye, M.A.(2015). Characteristics and Vulnerability of Houses under.World Environment; 5(3): 121-133; DOI: 10.5923/j.env.20150503.04

Olugbamila, O.B. (2018). Spatial Distribution and Accessibility to Healthcare Facilities in Akure South Local Government Area of Ondo State, Nigeria. AnaleleUniversitatii din Oradea, SeriaGeografie $7-18$.

Ritter, S., Paris, D., \& Lopes, C. N. L. (2018). Housing flexibility problem: Review of recent limitations and solutions; 80-91; Frontiers of Architectural Research, 7(1), https://doi.org/10.1016/j.foar.2017.11.004.

Rosel, L. (2020). osepBohigas: "El confinament fa que ensreplantegem la manera de relacionar-nosamb la família, els. ARA .

Saadat, S., Rawtani, D., \& Hussain, C. (2020). The environmental perspective of COVID-19. The Science of the Total EnvironmentArticle 138870.

Salje, H., Lessler, J., Paul, K.K., Azman, A.S., Rahman, M.W., Cummings, D., Gurley, E.S., Cauchemez, S. (2016). How social structures, space, and behaviors shape the spread of infectious diseases using chikungunya as a case study. PNAS, 113(47); 13420 - 13425; doi:10.1073/pnas.1611391113.

Van der Berg, R. (2020). How will COVID-19 affect urban planning? The City Fix.

Wainwright, O. (2020). Smart lifts, lonely workers, no towers or tourists: Architecture after coronavirus. . The Guardian: available at https://www.theguardian.com/artanddesign/2020/apr/13/smart-lifts-lonely-workers-no-towers-architecture-after-covid-19coron (Assessed 13 December 2020).

Watts, D.J., Muhamad, R., Medina, D.C., Dodds, P.S. (2005. ). Multiscale, resurgent epidemics in a hierarchical metapopulation model. Proc. Natl. Acad. Sci. U. S. A. 102(32), 11157-11162 